\title{
Review Article \\ Rare Earth Doped Apatite Nanomaterials for Biological Application
}

\author{
Thalagalage Shalika Harshani Perera, ${ }^{1,2}$ Yingchao Han, ${ }^{1}$ Xiaofei Lu, ${ }^{1}$ Xinyu Wang, \\ Honglian Dai, ${ }^{1}$ and Shipu $\mathrm{Li}^{1,3}$ \\ ${ }^{1}$ Biomedical Materials and Engineering Center, Wuhan University of Technology, Wuhan 430070, China \\ ${ }^{2}$ Faculty of Applied Sciences, Sabaragamuwa University of Sri Lanka, 70140 Belihuloya, Sri Lanka \\ ${ }^{3}$ State Key Laboratory of Advanced Technology for Materials Synthesis and Processing, 122 Luoshi Road, Wuhan 430070, China \\ Correspondence should be addressed to Yingchao Han; hanyingchao@whut.edu.cn
}

Received 3 July 2014; Accepted 2 October 2014

Academic Editor: Daniela Predoi

Copyright (C) 2015 Thalagalage Shalika Harshani Perera et al. This is an open access article distributed under the Creative Commons Attribution License, which permits unrestricted use, distribution, and reproduction in any medium, provided the original work is properly cited.

\begin{abstract}
In most biological analyses, a sensitive detection technique is primarily dependent on the fluorescence labeling agent. New generation of fluorophores called rare earth doped apatite nanoparticle (REAnp) has the ability to emit near infrared radiations which are of low absorptivity by tissue chromophores and especially suitable for biological system imaging. Moreover, bioapatite is demonstrated to be an excellent candidate for biomedical applications because of its biocompatibility, biodegradability, and bioactivity. During recent years a lot of efforts have been made for achievement of REAnp for medical diagnostics and targeted therapeutics applications. In this review, we discuss the significance of REAnps in biological systems, different root of synthesis, and biological applications. Also we discuss the future studies for the effective biological applications of REAnps.
\end{abstract}

\section{Introduction}

The apatite group is a group of similar isomorphous hexagonal minerals and can be commonly found in nature as both geological materials and biominerals in calcified tissues. Apatite generally has the formula $\mathrm{M}_{10}\left(\mathrm{TO}_{4}\right)_{6} \mathrm{X}_{2}$, with a hexagonal symmetry (space group $\mathrm{P}_{3} / \mathrm{m}$ ), where $\mathrm{M}$ is a large divalent cation $\left(\mathrm{Ca}^{2+}, \mathrm{Sr}^{2+}, \mathrm{Pb}^{2+}\right.$, etc. $), \mathrm{TO}_{4}$ is a trivalent anionic group $\left(\mathrm{PO}_{4}{ }^{3-}, \mathrm{SiO}_{4}{ }^{3-}, \mathrm{VO}_{4}{ }^{3-}\right.$, etc. $)$, and $\mathrm{X}$ is usually a monovalent anion $\left(\mathrm{F}^{-}, \mathrm{OH}^{-}\right.$, etc.) [1]. As a mineral, apatite is mainly used as a phosphorus source for the manufacture of fertilizers, for fluoridating water, and a protective coat on metals to prevent rust and used to remove radioactive as well as metallic contaminants from waste water and polluted soil $[2,3]$. The last decade has in particular witnessed the birth or evaluation of numerous biomaterials based on apatite. With the progress of nanotechnology, the decrease of particle size of apatite host can result in important modification of their properties which are significantly different from those of microsized hosts because of quantum confinement effect and surface effect of nanometer materials. Apatite nanoparticles (Anps) demonstrate favorable biodegradability and biocompatibility, affinity to biopolymers, and high osteogenic and low toxicity [4]. Therefore this bioapatite has been extensively used in biomedical field for hard tissue repair and replacement, drug/gene delivery, and tumor treatments [59]. Nanodimension allows the prolonged circulation in the blood stream escaping the capture from macrophages and the accumulation at the tumor site by "passive targeting" through the enhanced permeability and retention effect as nanocarrier [10]. Moreover it shows high stability in normal cellular $\mathrm{pH}$ environment but degradable at acidic environment specially in tumor region which allows drug release $[6,7]$. Another very important characteristic of nanosized bioapatite is its structural capacity to accept many ionic substitutions such as lanthanide ions as luminescent centers for offering an environment to sensitize the fluorescence of the dopant ions $[11,12]$.

The labeling or staining, especially the fluorescent labeling, has been demonstrated as an indispensable tool in the 
study of complex biological interaction. Traditional fluorescence cell labeling procedures in cell biology were mainly based on organic dyes, fluorescent proteins, and lanthanide chelates, which were prone to problems such as short lifetime, broad spectrum profiles, poor photochemical stability and photobleaching thresholds, potential toxicity to the cells, and simultaneous detection of multiple signals [13]. Therefore last few decades a lot of investigations have been conducted to find novel biological luminescent labeling methods for medical diagnostics and targeted therapeutics applications. In this context, use of quantum dots for cell labeling achieves much more attentions [14]. However, the photoblinking and high cytotoxicity limited their application for cell labelling and they require surface modification for improving biocompatibility [15]. Rare earth doped apatite nanoparticles (REAnps) show several advantageous properties such as long fluorescence lifetime, high quantum yield, sharp emission peaks, color tuning depending on the ions doped, and good resistance to photobleaching from environmental and other factors [16]. Therefore REAnps are hopeful to become excellent cell labels.

In view of the growing interest in the lanthanide ions doped Anps for biomedical application, this review article will discuss apatite environment for holding RE ions, different procedures of preparation of Anp with rare earth ions, and biological application of luminescent Anps. Currently identified challenges for use REAnps in biological environment and perspectives of these nanoparticles are also discussed at the end of this review.

\section{The Characteristics of the Lanthanide Doped Apatite Nanoparticles}

The physical, chemical, and biological properties of apatite are controlled by its crystal structure and composition. One of the main characteristics of apatite is capable to be substituted by other metal ions for calcium ions, which can endue the new properties for apatite [17]. The elements in the lanthanide series have gained huge attention due to their unique optical characteristics, especially as a fluorophore in a variety of biological applications $[18,19]$. Their unique optical properties arise from electronic transitions within the $4 \mathrm{f}$ shell or from $4 \mathrm{f}$ to $5 \mathrm{~d}$ shell [20]. These fluorophores can absorb light of a specific wavelength and reemit a quantum of light with an energy corresponding to the energy difference between the excited state and the ground state [21]. The extreme stability of lanthanides is attributed to the electronic transitions occurring in the ions, as compared to the involvement of chemical bonds in organic fluorophores and fluorescent proteins. As a host material, apatite provides a crystal lattice, which can fit the dopant ions so that the ions are held tightly in the crystal. Recent progress in nanoscience has enabled scientist to develop new fluorescent rare earth doped inorganic nanomaterials as cell labels with the detectable and stable fluorescent signal for understanding the complex and dynamic biological interaction at the molecular level [22].

The presence of multiple metastable states in lanthanide ions makes them good candidates for upconversion. Due to their unique characteristic of absorbing Near Infrared (NIR) light and emitting in the visible region paved way for their exploration in biological applications [23]. Upconversion is very well suited for biological application because NIR light does not excite any tissue components and hence there is almost zero background autofluorescence, which is especially advantageous in microscopic techniques. The use of NIR light for exciting the nanoparticles also offers high tissue penetration depth compared to Ultra Violet and visible light, enabling high resolution in vivo imaging. The phototoxicity from NIR is negligible [24]. REAnps show excellent photostability, chemical stability, and the thermal stability. Good photostability ensures long term tracking of these nanoparticles, which is not possible in conventional organic fluorescent labels with very quick photobleach. They also do not exhibit the phenomenon of "on-off" photoblinking, which is prevalent in quantum dots and causes the loss of information about the process under study when it is in an "off" state [25]. These particles can also be turned to emit various colors depending on the type of lanthanide dopant ions. The commonly used lanthanide ions for doping are $\mathrm{Ce}^{3+}, \mathrm{Pr}^{3+}, \mathrm{Nd}^{3+}, \mathrm{Sm}^{3+}, \mathrm{Eu}^{3+}, \mathrm{Tb}^{3+}, \mathrm{Dy}^{3+}, \mathrm{Er}^{3+}, \mathrm{Tm}^{3+}$, and $\mathrm{Yb}^{3+}$ [26]. Additionally, the codoping of rare earth elements such as $\mathrm{Eu}^{3+}$ and $\mathrm{Gd}^{3+}$ can enhance the NIR emission and the luminescence intensity can be adjusted by changing the doping element ratio. The NIR emission is of low absorptivity by tissue chromophores and especially suitable for biological system [27].

Other than these luminescent properties, rare earth elements also lead to some changes about physical-chemical properties of apatite nanoparticles. For example, the doping of rare earth elements such as $\mathrm{Eu}^{3+}$ normally caused the size decrease in cross-section direction of needle-like hydroxyapatite crystals and inhibited the crystallinite of apatite [1]. These changes also influence the solubility as well as the biological properties of apatite to some extent. However, these are not the main content in this paper. So we do not discuss them here in detail.

\section{Synthesis of REAnps}

The biological properties of various Anps used in in vitro and in vivo applications are strongly depended on their structural characteristics [28]. Therefore, it is important to select suitable method to synthesize Anps for application at cellular level. There are two main approaches for the synthesis of nanoparticles called top-down and bottom-up. Top-down approach refers to break down of bulk materials to get a nanosized particles. Nanosized materials build up from the basic chemical reaction called as bottom-up approach [29]. Most of published researches normally use bottom-up approach to synthesize Anps for the biomedical application due to their potential ability to load various agents, that is, therapeutic, bioimaging, and so forth [30,31]. According to the literature, there are several methods reported to prepare RE doped apatite particles for biomedical application such as solid state synthesis method, chemical precipitation method, and sol gel method. 
3.1. Solid State Reaction. As a simple procedure, solid state reaction can be employed in the mass production of apatite particles. Generally the first procedure is to mix and mill the raw materials in solid state and then calcine the mixture at a very high temperature of more than $1000^{\circ} \mathrm{C}$. This high calcination temperature leads to the formation of RE doped apatite with well crystallized structure [32,33]. However, solid state method is not suited for preparing REAnps because apatite particles generated from solid state method are usually large in size and irregular in shape. The relatively large particles are not easily internalized by living cells and cannot be used in biological application [29].

3.2. Coprecipitation Method. Nowadays, the precise preparation of nanoscale particles with controllable sizes and well defined morphologies remains a significantly challenging issue [34]. As a typical solution based approach, chemical precipitation method is identified as an effective and convenient way to prepare various apatite biomaterials with tunable architectures and morphologies, attributed to its mild reaction conditions, ease of operation, and large scale production capabilities [35]. Moreover, reaction can be performed at a number of synthesis ways involving diverse chemicals, apparatus, and using auxiliary additives. Various researches had discussed the effects of synthesis parameters such as temperature, time, reaction concentration, calcination procedures, and use of different reagents on the morphological properties of these nanoparticles.

The luminescent $\mathrm{Eu}^{3+}$ ion doped calcium hydroxyl apatite was prepared using a precipitation reaction followed by high calcined temperature $\left(950^{\circ} \mathrm{C}\right)[36]$. Although samples showed good luminescence, due to use of high temperature, the particle size of the crystals was large and not at nanoscale level, which was unfavorable for biological application. Subsequently, researchers focused on the effect of temperature on the particle size and luminescence property. Mondejar at el. obtained lanthanide doped nanoparticles by precipitation method. They used two different reaction temperatures of $37^{\circ} \mathrm{C}$ and $80^{\circ} \mathrm{C}$ and a calcined temperature of $1100^{\circ} \mathrm{C}$. As a result of heat treatment, the thermal diffusion of the fluorescent ions to the crystallographic site of $\mathrm{Ca}^{2+}$ occurred and consequently a strong emission was achieved. According to the fluorescence emission, the sample calcined at $1100^{\circ} \mathrm{C}$ would be the most suitable one to be used as fluorescent labels due to its strong luminescence; however, the particle size of this sample is larger than $1 \mu \mathrm{m}$, which is not suitable for cellular uptake. In contrast, the particle size of the samples obtained at $37^{\circ} \mathrm{C}$ lies between 20 and $50 \mathrm{~nm}$, but their fluorescence is weak. Therefore the nanocrystalline samples obtained at $80^{\circ} \mathrm{C}$ without additional heat treatment represent a good compromise between fluorescence and biologically necessary particle size [37].

Consequently, coprecipitation method without high temperature calcination attracted more attentions for preparing REAnps. Doat at el. synthesized europium doped Anps at $37^{\circ} \mathrm{C}$ by coprecipitation in water-ethanol medium. This apatite showed hydrogen phosphate ions rich, calcium deficient, and poorly crystallized nanosized crystals which were similar to the mineral component of calcified tissues of living organisms and thus a biomimetic material [38]. Some researchers synthesized luminescent europium doped hydroxyapatite nanocrystals by coprecipitation method followed by a heating at temperature around $100^{\circ} \mathrm{C}[1,11$, 39]. They obtained biomimic apatitic particles with the best economical way.

In addition, the properties such as morphology and luminescence of REAnps can be controlled by coprecipitation method. Ciobanu et al. prepared europium doped hydroxyapatite nanocrystals using simple coprecipitation method at low temperature with different atomic ratios of $\mathrm{Eu}^{3+}$ and $\mathrm{Ca}^{2+}$ ions. According to their results $\mathrm{Eu}^{3+}$ has been successfully doped into hydroxy-Anps and doping $\mathrm{Eu}^{3+}$ ions little influence the ellipsoidal morphology [39]. However, other studies showed that as the $\mathrm{Eu}^{3+}$ concentration was increased to $20 \%$ the emission spectrum became broaden, suggesting that the doping inhibits the apatite crystal growth and/or causes lattice perturbations (microstrain) [1]. At low concentration of $\mathrm{Eu}^{3+}$, the sample showed less intense $\mathrm{Eu}^{3+}$ related red emissions at $590 \mathrm{~nm}$ and $616 \mathrm{~nm}$, whereas, with increased doping, the emission intensity was increased significantly with better spectral resolution. They emphasized that more efficient intensity was found at $700 \mathrm{~nm}$ in $2 \%$ and $3 \%$ of $\mathrm{Eu}^{3+}$ concentration [26]. Ternane et al. reported that $\mathrm{Ce}^{3+}$ luminescence in well characterized calcium borohydroxyapatite for different boron content and due to introduction of borate groups causes an increase in structural disorder and a shift of the emission bands to longer wavelengths resulting in sharp luminescence intensity [40].

3.3. Sol Gel Method. Sol gel offers advantages of molecular level mixing of reactants, improving the chemical homogeneity of the resulting powder, small crystal size ranging from $50 \mathrm{~nm}$ to $1 \mu \mathrm{m}$ (depending on synthesis parameters), and excellent bioresorbability [41]. However only a few studies directly focused on the sol gel synthesis method because it is required to calcine the dried gel to remove the harmful component and form apatite crystals at high temperature $[18,42]$.

3.4. In-Situ and Ex-Situ Doping of RE. According to reported documents there are many strategies that have been employed to load rare earth element ions to nanosized apatite lattice. Generally, these strategies can be broadly summarized into two groups: doping RE ions during the synthesis of apatite nanoparticles called as in-situ doping and doping RE ions after synthesis of apatite nanoparticles called as ex-situ doping [43]. In-situ doping of RE ions in apatite is well documented in the literature and most of research works report synthesis method of lanthanide doped Anps is mainly using chemical precipitation method [32, 33, 37, 38, 44].

A careful survey of literature shows that only a few researchers have used ex-situ doping for synthesis RE labeled Anps [45-47]. They especially used ex-situ doping for apatite particles to make radiolabeled particles. However, the ex-situ 
loading technique has generally a lower loading efficiency as compared to the in-situ techniques.

\section{Biological Applications}

Optical materials have much attention due to their importance in the fields of biology, chemistry, medical science, material science, and biotechnology. The performances of REAnps mainly depend on their morphologies, structure, and chemical compositions [48]. RE doped nanoparticles have been investigated in a wide range of biological applications such as imaging, immunocytochemistry, DNA detection. Fluorescence microscopy involves the visualization of cells or cellular components with subcellular resolution by labeling them with fluorescent probes [49].

Imaging of live cells and their various cellular components and tracking specific biomolecules are essential parts of cell and molecular biology. The REAnps show stable luminescence and possess NIR radiation. They provide a high signal to noise ratio, strong penetration ability, and less photo damage to the cell and tissue which has great advantages in cell and tissue imaging [50].

Han et al. demonstrated $\mathrm{Eu}^{3+}$ doped HAP nanoparticles for labeling of Bel-7402 human liver cancer cells. After internalization by cells they could observe strong green fluorescence and red fluorescence with excitation of blue light and green light, respectively, in the visible region. They also found that after $6.5 \mathrm{~h}$ incubation time the fluorescence intensity showed a trend to decline slowly due to activity of lysosome inside the cell, indicating that the intracellular degradation of apatite nanoparticles might be tracked by the change of fluorescence [43]. Therefore, they showed that Eu-HAP nanoparticles have the potential as valuable biocompatible fluorescent labeling material in biological studies.

Doat et al. showed europium doped apatitic tricalcium phosphate in human epithelial cells detected by confocal microscopy with the aid of its stable luminescence. Therefore these nanoparticles show interesting luminescent probe for observing the traffic and grafted biomolecules in cells [18]. Niu et al. and colleagues monitored strontium fluorapatite doped with $\mathrm{Tb}^{3+}$ or $\mathrm{Eu}^{3+}$ samples gives characteristics emissions even after the loading of organic drug molecules and they suggested its feasible possibility to be monitored or tracked during the drug release and disease therapy process [51]. RE doped Anps can be used as a tracking device for the particle and give an observable indication of agent delivery, while the nanoparticle can serve to protect the agent in vivo until it has reached the destination.

Anps have been explored in research as feasible delivery platforms for therapeutic applications. Hydroxyapatite (HAP) is of particular interest due to its appealing attributes such as interconnecting porosity of bulk material, good biocompatibility, resistance to mechanical force, and sustained release capacity. Thus, HAP nanoparticles are actively being investigated for drug delivery [27, 52], gene and siRNA delivery [53], and immunoadjuvant therapy. And also HAP nanoparticles can deliver therapeutic drugs, antigens, and proteins without degradation and can release them in proper place at a slow rate [54]. And also it can be functionalized with special characteristics for qualitative or quantitative detection of tumor cells [55]. Chen et al. and group developed $\mathrm{Eu}^{3+}$ and $\mathrm{Gd}^{3+}$ dual doped calcium phosphate in the presence of amphiphilic block copolymer and demonstrated imaging and drug release capacity. They showed their hybrid material can be used as the drug nanocarriers and have a high drug loading capacity and ultralong sustained drug release using ibuprofen as a model drug, and the drug release from the drug delivery system can sustain for a very long period of time more than 80 days [27]. REAnps have been applied as nonviral carriers for drug delivery and gene therapy. After loading with genes or drugs, REAnps provide a protective environment that shields them from degradation while providing a convenient pathway for cell membrane penetration and controlled release of the genes and drugs. The experimental results proved that Anp possessed a higher penetration rate into cell membrane and their transfection efficiency could be 25 -fold higher than that of the micron-sized particles [4].

\section{Conclusion and Perspectives}

To optimize and achieve better performances, controlling the structure and size of nanostructured apatite materials has become a hot field. This account summarizes some recent progress on the synthesis, properties, and application of lanthanide doped Anps. Up to now, many synthesis methods have been reported and in-situ precipitation method is identified as effective method. Frequently to obtain well diffused RE ion in apatite structure, precipitation method followed by high temperature around $1000^{\circ} \mathrm{C}$ is required. But this much of high temperature causes production of large particle size of apatite particles and it may not interline with biological applications. Because research on lanthanide doped apatite particles is still in its infancy, many of the efficient synthesis procedures are yet to be discovered. Currently some of investigators try to use macromolecular such as PEI (polyethyleneimine), DNA, PEG (polyethylene glycol), and PAA (polyacrylic acid) to eliminate use of high temperature step and obtain well diffused RE ions in apatite structure. But further experiments are required to select the most appropriate stabilizer for this.

Also there is growing interest in the trace method of luminescent Anps within biological system. Luminescent property of the lanthanide ions can be used to trace Anps within the biological system. There are more experiments conducted to check cytotoxicity of Anp at the cellular level and fortunately they still could obtain positive results. But further investigation should find out biodistribution and final destination of these particles. Additionally, due to their excellent favorable osteoconductive and bioactive properties, Anps are preferred as the inorganic component of composite biomaterials $[56,57]$, which are valuable for bone grafting and drug delivery. So, REAnp in the composite biomaterials might be used as contrast agent to monitor the bone regeneration in vivo. On the other hand there are a number of 
challenges ahead in the practical applications of REAnps such as the luminescent efficiency, biological compatibility, and stability within biological systems.

\section{Conflict of Interests}

The authors declare that there is no conflict of interests regarding the publication of this paper.

\section{Acknowledgments}

This work was supported by the National Natural Science Foundation of China (51002109, 81190133, and 51172171), the Fundamental Research Funds for the Central Universities (WUT: 2014-IV-121, 2014-VII-028), and the project supported by State Key Laboratory of Advanced Technology for Materials Synthesis and Processing (Wuhan University of Technology).

\section{References}

[1] C. S. Ciobanu, F. Massuyeau, E. Andronescu, M. S. Stan, A. Dinischiotu, and D. Predoi, "Biocompatibility study of europium doped crystalline hydroxyapatite bioceramics," Digest Journal of Nanomaterials and Biostructures, vol. 6, no. 4, pp. 1639-1647, 2011.

[2] C. S. Ciobanu, C. L. Popa, and D. Predoi, "Sm:HAp nanopowders present antibacterial activity against Enterococcus faecalis," Journal of Nanomaterials, vol. 2014, Article ID 780686, 9 pages, 2014.

[3] Z. Li, M.-M. Zhou, and W. Lin, "The research of nanoparticle and microparticle hydroxyapatite amendment in multiple heavy metals contaminated soil remediation," Journal of Nanomaterials, vol. 2014, Article ID 168418, 8 pages, 2014.

[4] S. V. Dorozhkin, "Nanodimentional and nanocystalline calcium orthophosphates," American Journal of Biomedical Engineering, vol. 2, no. 3, pp. 48-97, 2012.

[5] R. Z. LeGeros and J. P. LeGeros, "Calcium phosphate bioceramics: past, present and future," Key Engineering Materials, vol. 240-242, pp. 3-10, 2003.

[6] S. Tada, E. H. Chowdhury, C.-S. Cho, and T. Akaike, "pHsensitive carbonate apatite as an intracellular protein transporter," Biomaterials, vol. 31, no. 6, pp. 1453-1459, 2010.

[7] E. V. Giger, J. Puigmartí-Luis, R. Schlatter, B. Castagner, P. S. Dittrich, and J.-C. Leroux, "Gene delivery with bisphosphonatestabilized calcium phosphate nanoparticles," Journal of Controlled Release, vol. 150, no. 1, pp. 87-93, 2011.

[8] M.-Z. Yin, Y.-C. Han, I. W. Bauer, P. Chen, and S.-P. Li, "Effect of hydroxyapatite nanoparticles on the ultrastructure and function of hepatocellular carcinoma cells in vitro," Biomedical Materials, vol. 1, no. 1, pp. 38-41, 2006.

[9] M. Yin, Y. Yin, Y. Han, H. Dai, and S. Li, "Effects of uptake of hydroxyapatite nanoparticles into hepatoma cells on cell adhesion and proliferation," Journal of Nanomaterials, vol. 2014, Article ID 731897, 7 pages, 2014.

[10] Y. Chen and H. Liang, "Applications of quantum dots with upconverting luminescence in bioimaging," Journal of Photochemistry and Photobiology B: Biology, vol. 135, pp. 23-32, 2014.

[11] I. Mayer, J. D. Layani, A. Givan, M. Gaft, and P. Blanc, "La ions in precipitated hydroxyapatites," Journal of Inorganic Biochemistry, vol. 73, no. 4, pp. 221-226, 1999.
[12] P. Martin, G. Carlot, A. Chevarier, C. Den-Auwer, and G. Panczer, "Mechanisms involved in thermal diffusion of rare earth elements in apatite," Journal of Nuclear Materials, vol. 275, no. 3, pp. 268-276, 1999.

[13] F. Wang, W. B. Tan, Y. Zhang, X. Fan, and M. Wang, "Luminescent nanomaterials for biological labelling," Nanotechnology, vol. 17, no. 1, pp. R1-R13, 2006.

[14] O. Akinfieva, I. Nabiev, and A. Sukhanova, "New directions in quantum dot-based cytometry detection of cancer serum markers and tumor cells," Critical Reviews in Oncology/Hematology, vol. 86, no. 1, pp. 1-14, 2013.

[15] S. Ranjbarvaziri, S. Kiani, A. Akhlaghi, A. Vosough, H. Baharvand, and N. Aghdami, "Quantum dot labeling using positive charged peptides in human hematopoetic and mesenchymal stem cells," Biomaterials, vol. 32, no. 22, pp. 5195-5205, 2011.

[16] M. Manoharan, "Research on the frontiers of materials science: the impact of nanotechnology on new material development," Technology in Society, vol. 30, no. 3-4, pp. 401-404, 2008.

[17] J. Rakovan and R. J. Reeder, "Intracrystalline rare earth element distributions in apatite: surface structural influences on incorporation during growth," Geochimica et Cosmochimica Acta, vol. 60, no. 22, pp. 4435-4445, 1996.

[18] A. Doat, M. Fanjul, F. Pellé, E. Hollande, and A. Lebugle, "Europium-doped bioapatite: a new photostable biological probe, internalizable by human cells," Biomaterials, vol. 24, no. 19, pp. 3365-3371, 2003.

[19] B. Basar, A. Tezcaner, D. Keskin, and Z. Evis, "Improvements in microstructural, mechanical, and biocompatibility properties of nano-sized hydroxyapatites doped with yttrium and fluoride," Ceramics International, vol. 36, no. 5, pp. 1633-1643, 2010.

[20] H. Bazin, M. Préaudat, E. Trinquet, and G. Mathis, "Homogeneous time resolved fluorescence resonance energy transfer using rare earth cryptates as a tool for probing molecular interactions in biology," Spectrochimica Acta A: Molecular and Biomolecular Spectroscopy, vol. 57, no. 11, pp. 2197-2211, 2001.

[21] J. G. Bünzli, S. Comby, A.-S. Chauvin, and C. D. B. Vandevyver, "New opportunities for lanthanide luminescence," Journal of Rare Earths, vol. 25, no. 3, pp. 257-274, 2007.

[22] Y. Lü, Y. Li, D. Zhao, L. Zhang, and S. Zhong, "Uniform YF 3 nanorods: synthesis, luminescent properties and cytotoxicity study," Journal of Rare Earths, vol. 29, no. 11, pp. 1036-1039, 2011.

[23] F. Wang and X. Liu, "Recent advances in the chemistry of lanthanide-doped upconversion nanocrystals," Chemical Society Reviews, vol. 38, no. 4, pp. 976-989, 2009.

[24] J. H. Rao, A. Dragulescu-Andrasi, and H. Q. Yao, "Fluorescence imaging in vivo: recent advances," Current Opinion in Biotechnology, vol. 18, no. 1, pp. 17-25, 2007.

[25] E. Chang, N. Thekkek, W. W. Yu, V. L. Colvin, and R. Drezek, "Evaluation of quantum dot cytotoxicity based on intracellular uptake," Small, vol. 2, no. 12, pp. 1412-1417, 2006.

[26] R. Reisfeld, M. Gaft, G. Boulon, C. Panczer, and C. K. Jørgensen, "Laser-induced luminescence of rare-earth elements in natural fluor-apatites," Journal of Luminescence, vol. 69, no. 5-6, pp. 343353, 1996.

[27] F. Chen, P. Huang, Y. J. Zhu, J. Wu, and D. X. Cui, "Multifunctional $\mathrm{Eu}^{3+} / \mathrm{Gd}^{3+}$ dual doped calcium phosphate vesicle like nanosperes for sustained drug release and imaging," Biomaterials, vol. 33, pp. 6447-6455, 2012.

[28] D. Gopi, S. Ramya, D. Rajeswari, P. Karthikeyan, and L. Kavitha, "Strontium, cerium co-substituted hydroxyapatite nanoparticles: synthesis, characterization, antibacterial activity towards 
prokaryotic strains and in vitro studies," Colloids and Surfaces A: Physicochemical and Engineering Aspects, vol. 451, no. 1, pp. 172-180, 2014.

[29] S. C. J. Loo, T. Moore, B. Banik, and F. Alexis, "Biomedical applications of hydroxyapatite nanoparticles," Current Pharmaceutical Biotechnology, vol. 11, no. 4, pp. 333-342, 2010.

[30] J. Gómez-Morales, M. Iafisco, J. M. Delgado-López, S. Sarda, and C. Drouet, "Progress on the preparation of nanocrystalline apatites and surface characterization: overview of fundamental and applied aspects," Progress in Crystal Growth and Characterization of Materials, vol. 59, no. 1, pp. 1-46, 2013.

[31] S. V. Dorozhkin, "Nanosized and nanocrystalline calcium orthophosphates," Acta Biomaterialia, vol. 6, no. 3, pp. 715-734, 2010.

[32] R. El Ouenzerfi, N. Kbir-Ariguib, M. Trabelsi-Ayedi, and B. Piriou, "Spectroscopic study of $\mathrm{Eu}^{3+}$ in strontium hydroxyapatite $\mathrm{Sr}_{10}\left(\mathrm{PO}_{4}\right)_{6}(\mathrm{OH})_{2}$," Journal of Luminescence, vol. 85, no. 1-3, pp. 71-77, 1999.

[33] Y. Han, X. Wang, H. Dai, and S. Li, "Synthesis and luminescence of $\mathrm{Eu}^{3+}$ doped hydroxyapatite nanocrystallines: effects of calcinations and $\mathrm{Eu}^{3+}$ content," Journal of Luminescence, vol. 135, pp. 281-287, 2013.

[34] G. Wang, Q. Peng, and Y. Li, "Lanthanide-doped nanocrystals: synthesis, optical-magnetic properties, and applications," Accounts of Chemical Research, vol. 44, no. 5, pp. 322-332, 2011.

[35] M. Sadat-Shojai, M. T. Khorasani, E. Dinpanah-Khoshdargi, and A. Jamshidi, "Synthesis methods for nanosized hydroxyapatite with diverse structures," Acta Biomaterialia, vol. 9, no. 8, pp. 7591-7621, 2013.

[36] R. Ternane, M. Trabelsi-Ayedi, N. Kbir-Ariguib, and B. Piriou, "Luminescent properties of $\mathrm{Eu}^{3+}$ in calcium hydroxyapatite," Journal of Luminescence, vol. 81, no. 3, pp. 165-170, 1999.

[37] S. P. Mondéjar, A. Kovtun, and M. Epple, "Lanthanide-doped calcium phosphate nanoparticles with high internal crystallinity and with a shell of DNA as fluorescent probes in cell experiments," Journal of Materials Chemistry, vol. 17, no. 39, pp. 4153-4159, 2007.

[38] A. Doat, F. Pellé, N. Gardant, and A. Lebugle, "Synthesis of luminescent bioapatite nanoparticles for utilization as a biological probe," Journal of Solid State Chemistry, vol. 177, no. 4-5, pp. 1179-1187, 2004.

[39] C. S. Ciobanu, S. L. Iconaru, F. Massuyeau, L. V. Constantin, A. Costescu, and D. Predoi, "Synthesis, structure, and luminescent properties of europium-doped hydroxyapatite nanocrystalline powders," Journal of Nanomaterials, vol. 2012, Article ID 942801, 9 pages, 2012.

[40] R. Ternane, M. T. Cohen-Adad, G. Panczer et al., "Structural and luminescent properties of new $\mathrm{Ce}^{3+}$ doped calcium borophosphate with apatite structure," Solid State Sciences, vol. 4, no. 1, pp. 53-59, 2002.

[41] M. H. Fathi and A. Hanifi, "Evaluation and characterization of nanostructure hydroxyapatite powder prepared by simple solgel method," Materials Letters, vol. 61, no. 18, pp. 3978-3983, 2007.

[42] Y. Han, X. Wang, S. Li, and X. Ma, "Synthesis of terbium doped calcium phosphate nanocrystalline powders by citric acid sol-gel combustion method," Journal of Sol-Gel Science and Technology, vol. 49, no. 1, pp. 125-129, 2009.

[43] Y. Han, X. Wang, and S. Li, "Biocompatible europium doped hydroxyapatite nanoparticles as a biological fluorescent probe," Current Nanoscience, vol. 6, no. 2, pp. 178-183, 2010.
[44] A. Ashokan, D. Menon, S. Nair, and M. Koyakutty, "A molecular receptor targeted, hydroxyapatite nanocrystal based multimodal contrast agent," Biomaterials, vol. 31, no. 9, pp. 26062616, 2010.

[45] S. Chakraborty, T. Das, H. D. Sarma, M. Venkatesh, and S. Banerjee, "Preparation and preliminary studies on ${ }^{177} \mathrm{Lu}-$ labeled hydroxyapatite particles for possible use in the therapy of liver cancer," Nuclear Medicine and Biology, vol. 35, no. 5, pp. 589-597, 2008.

[46] U. Pandey, K. Bapat, H. D. Sarma et al., "Bioevaluation of 90Ylabeled particles in animal model of arthritis," Annals of Nuclear Medicine, vol. 23, no. 4, pp. 333-339, 2009.

[47] T. Das, S. Chakraborty, H. D. Sarma, M. Venkatesh, and S. Banerjee, " ${ }^{166}$ Ho-labeled hydroxyapatite particles: A possible agent for liver cancer therapy," Cancer Biotherapy and Radiopharmaceuticals, vol. 24, no. 1, pp. 7-14, 2009.

[48] F. Chen, Y. Zhu, J. Wu, P. Huang, and D. Cui, "Nanostructured calcium phosphates: preparation and their application in biomedicine," Nano Biomedicine and Engineering, vol. 4, no. 1, pp. 41-49, 2012.

[49] M. Tourbin, A. Al-Kattan, and C. Drouet, "Study on the stability of suspensions based on biomimetic apatites aimed at biomedical applications," Powder Technology, vol. 255, pp. 17-22, 2014.

[50] I. R. Corrêa, "Live-cell reporters for fluorescence imaging," Current Opinion in Chemical Biology, vol. 20, pp. 36-45, 2014.

[51] N. Niu, D. Wang, S. Huang et al., "Controlled synthesis of luminescent F-substituted strontium hydroxyapatite with hierarchical structures for drug delivery," CrystEngComm, vol. 14, no. 5, pp. 1744-1752, 2012.

[52] H. T. Ong, J. S. C. Loo, F. Y. C. Boey, S. J. Russell, J. Ma, and K.-W. Peng, "Exploiting the high-affinity phosphonatehydroxyapatite nanoparticle interaction for delivery of radiation and drugs," Journal of Nanoparticle Research, vol. 10, no. 1, pp. 141-150, 2008.

[53] Y. Kakizawa, S. Furukawa, and K. Kataoka, "Block copolymercoated calcium phosphate nanoparticles sensing intracellular environment for oligodeoxynucleotide and siRNA delivery," Journal of Controlled Release, vol. 97, no. 2, pp. 345-356, 2004.

[54] Y. T. Li, M. J. Chua, A. P. Kunnath, and E. H. Chowdhury, "Reversing multidrug resistance in breast cancer cells by silencing $\mathrm{ABC}$ transporter genes with nanoparticle-facilitated delivery of target siRNAs," International Journal of Nanomedicine, vol. 7, pp. 2473-2481, 2012.

[55] A. Al-Kattan, S. Girod-Fullana, C. Charvillat et al., "Biomimetic nanocrystalline apatites: emerging perspectives in cancer diagnosis and treatment," International Journal of Pharmaceutics, vol. 423, no. 1, pp. 26-36, 2012.

[56] M. Ficai, E. Andronescu, D. Ficai, G. Voicu, and A. Ficai, "Synthesis and characterization of COLL-PVA/HA hybrid materials with stratified morphology," Colloids and Surfaces B: Biointerfaces, vol. 81, no. 2, pp. 614-619, 2010.

[57] A. Ficai, E. Andronescu, G. Voicu, C. Ghitulica, and D. Ficai, "The influence of collagen support and ionic species on the morphology of collagen/hydroxyapatite composite materials," Materials Characterization, vol. 61, no. 4, pp. 402-407, 2010. 

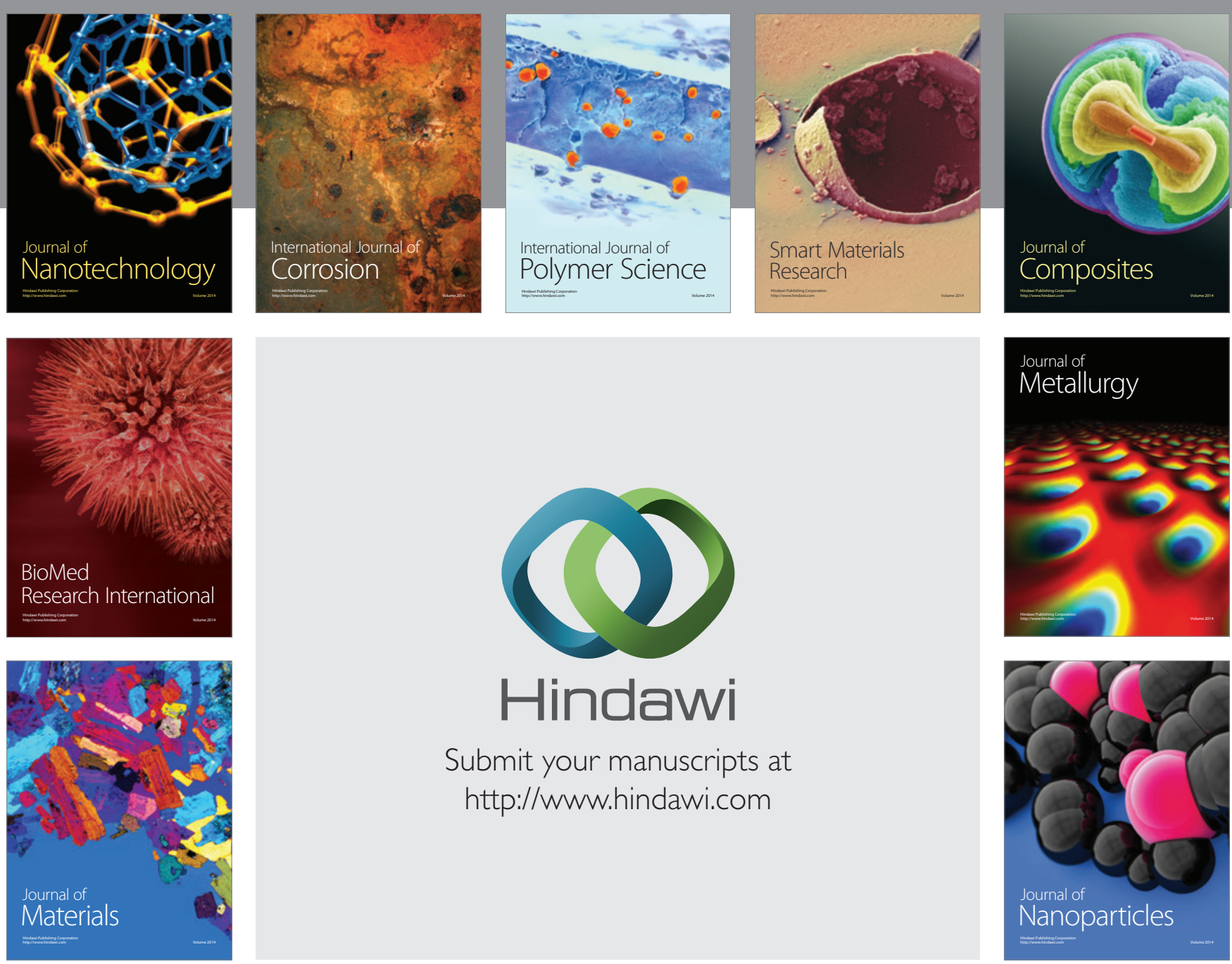

Submit your manuscripts at http://www.hindawi.com
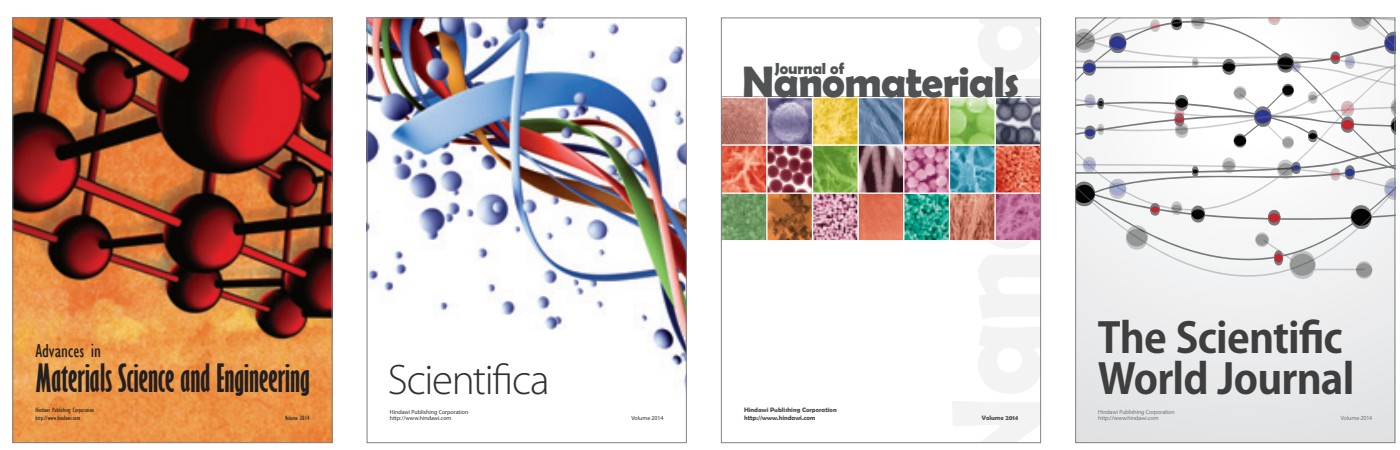

\section{The Scientific World Journal}
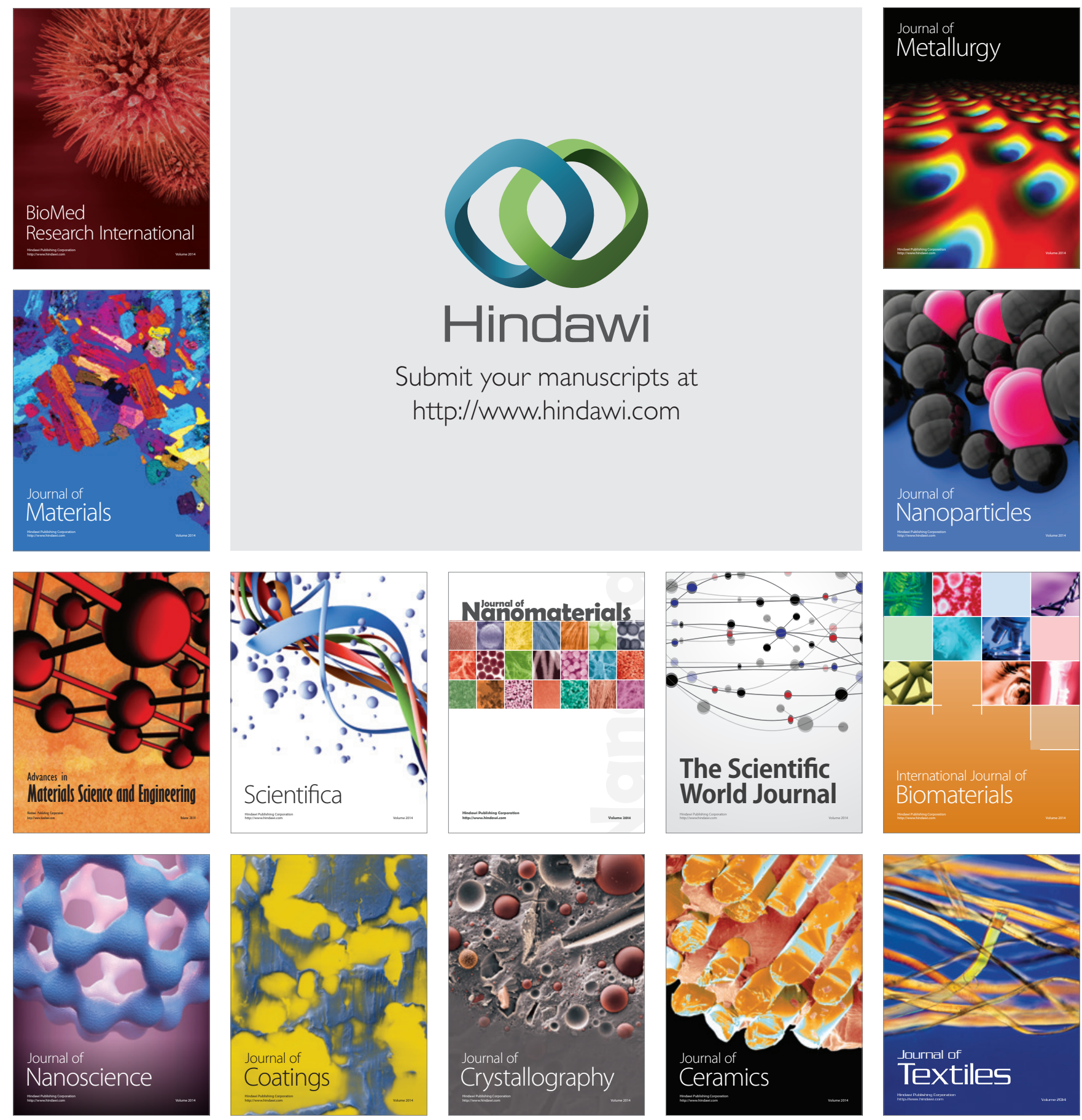